\title{
تعلم القواعد النحوية ومحاولة تيسيرها
}

\author{
Nasarudin \\ nasarmtdn@gmail.com \\ Universitas Muhammadiyah Mataram (UMMat)

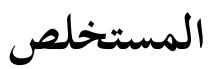

أهداف هذه الدراسة هي معرفة مفاهيم القواعد النحوية ومعرفة تيسير القواعد النحوية ومعرفة طريقة تعليم القواعد النحوية. ونتائج هذه الدراسة هي: القواعد النحوية تتكون من القواعد النظرية والقواعد الوظيفية. الأولى لثروة عالم المعارف النحوية والثانية تم تحديدها محتاجة إلى تعزيز ممارسة المهارات اللغوية؛ وتيسير القواعد النحوية من قبل النحاة خلال تصنيف الكتابة بروح التجديد النحوي؛ وطريقة تعليم القواعد النحوية أن تدمج المواد النحوية في تعليم المهارة اللغوية خاصة في القراءة والكتابة. الكلمات المفتاحية: تيسير النحو، طريقة التعليم، القواعد التطبيقية

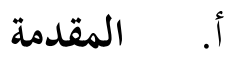

تعلم القواعد النحوية شيء مهم بناء على قول عمر بن الخطاب رضي الله عنه: تعلّموا النحو كما تتعلّمون السنة والفرائض. (معروف، 1991 : 181) مما لاشك فيه أن للنحو أهمية كبرى بين مختلف العلوم الإنسانية، فلا شك يمكن أن يستغنى عن معرفته، ذلك أنه ضروري ليكون القارئ قادراً على التمييز بين الألفاظ المتكافئة اللفظ، كما أن له الدور المهم في فهم المقروء ، وفي الاستماع والتعبير السليم، شفهياً كان أو كتابياً (طواهرية، 27).

ولكن النحو أحد علوم اللغة العربية حيث غالباً ما يحتج كثيرون بأن اللغة العربية لغة صعبة، بل يجعلونها اللغة الأصعب في العالم، إذ يصنف المتحدثون بالإنجليزية كلغة أولى اللغات الأخرى إلى سهلة ومتوسطة وصعبة؛ أما السهلة فهي اللغات المشابهة للإنجليزية والقريبة منها، مثل الإسبانية والبرتغالية والفرنسية والإيطالية، والمتوسطة هي اللغات ذات الفوارق الكبيرة عن الإنجليزية، مثل الهندية والروسية والتركية وغيرها؛ في حين تبدأ قائمة أصعب اللغات باللغة العربية ثم اليابانية والصينية والكورية، رغم أن هناك نحو 450 مليون شخص حول العالم يتكلمون اللغة العربية اليوم. وتُعزى صعوبة اللغة العربية إلى بعض ما تختص به على صعيد الإعراب: اللغة العربية معربة، وعلم النحو وهو علم يبحث في ما يطرأ على أواخر الكلمات من تغيرات وفق تغير موضع 
الكلمة في النص؛ وتكمن صعوبة تعلم النحو في الحشو والاهتمام بما لا يُستخدم ولا يُنتفع به، وعدم تدريس القواعد الوظيفية كما ينبغي (https://al-akhbar.com).

الواقع في الميدان أن المادة النحوية التي تدرس فيها تتكوّن من ثمانية حصص مدة أربع مراحل، ولكل المرحلة حصتان. وقد نظر المحاضر الجامعي أن تعليم النحو في الجامعة تكميل لتعليم النحو في المدرسة المتوسطة أو الثانوية. هذا يؤثّر في تعليم النحو في الجامعة، أي يدرس المحاضر فيها المواد النحوية الصعبة الكثيرة مع أنه لا يفهم الطلبة الأسس النحوية حينما تعلّموها في المدارس. هذا الواقع من الأسباب التي تجعل كفاءة نحو الطلبة في الجامعات ضعيفة. وأيضا، يكون تعليم المواد النحوية بدون أثر أو فائدة للطلبة مما يسبّب لهم مللا وكآبة ولايستمتعون بالدراسة وهذا يجعل جو الفصل غير فعال (نصار دين، 2015: 39-40).

إن المسألة لا تنحصر الآن بالنواحي اللغوية الشائكة كالندبة والاختصاص والنداء، بل إن طلبة المرحلة الثانوية يعجزون عن تصور الجملة الفعلية إذا استتر فاعلها، والاسمية إذا حذف خبرها أو مبتدؤها، ويعجزون عن تفسير عدمِ ظهورِ علامة الإعراب على أواخرِ بعض الكلمات مثلُ الأسماء المقصورة والمنقوصة وكذلك عدم تنوينِ الممنوع من الصرف ونصب اسم إن المؤخر ورفع اسم كان المؤخ (جاهمي، 2005: 4).

أغلب الدراسات التي أجريت حول مشكلات تعليم النحو توصلت الى ضعف الطلاب في مادة النحو بسبب محتوى النحو الذي يدرس غير مناسب لمستوى الطلاب لابدَّ من تبسيطه والمعلم غير مدرَّب وكثير من معلمي النحو من تخصص غير مباشر وطريقة التدريس غير مناسبة وأسلوب المعلم غير جاذب للطلاب وغير محبب لهم للمادة والاختبارات غير منتظمة وأغلب الطلاب ينفرون من مادة النحو وكذلك المعلمون (محمد وحبيب الله، 2015: 226).

\section{ب. مفاهيم القواعد النحوية}

ومن المعروف أن قاعدة النحو هي الشكل الذي ينتظم مفاهيم بحث نحوي معين وأنواعها وحالتها إذا وجدت، مقرونة بسماتها الجوهرية. ودورها يكمن في مساعدة الطلبة على التمييز بين التركيب الصحيح والمنحرف (عطا، 2005: 268). والقاعدة في النحو العربي كثيرة ولكن القواعد الأساسية هي الجملة الاسمية والجملة الفعلية. 


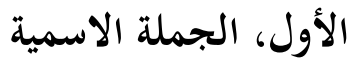

للجملة الاسمية ركنان أساسيان، لا يتم معناها إلا بهما معا، وهما المبتدأ والخبر

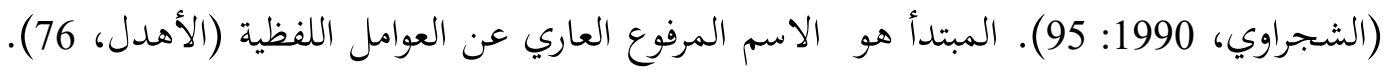

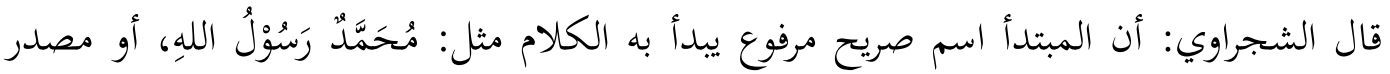

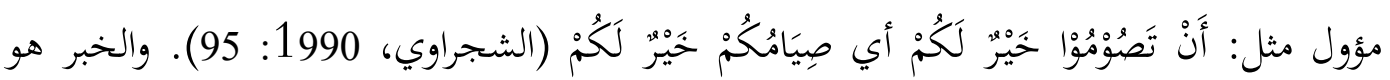

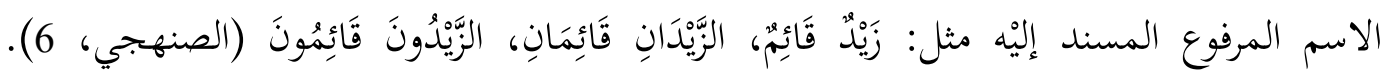

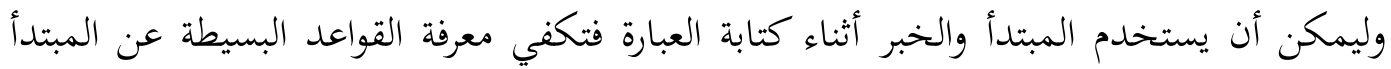

كما يكون المبتدأ اسم ذات علما أو اسم جنس معرَّفا بالألف واللام أو مضاف إلى معرفة،

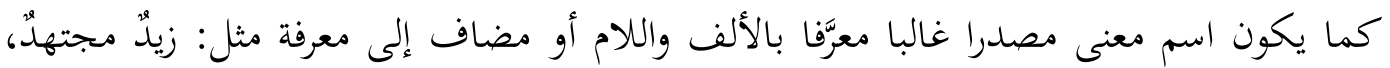

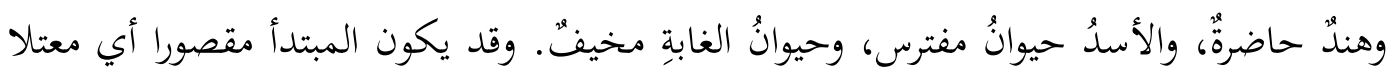

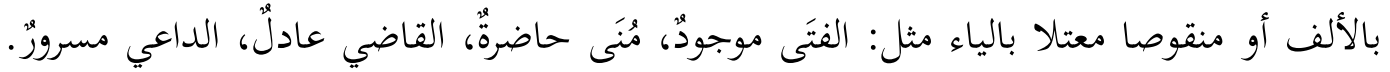

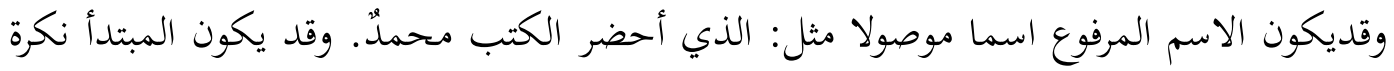

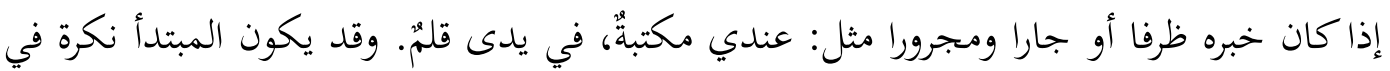

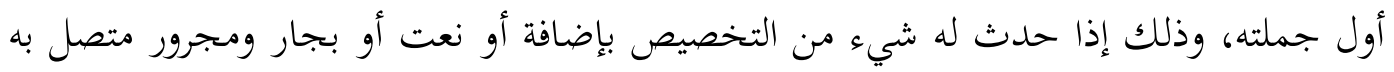

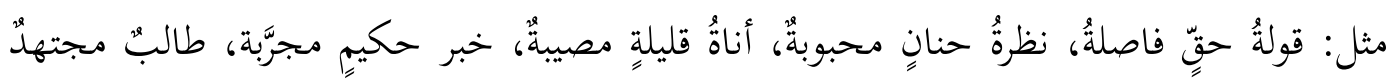

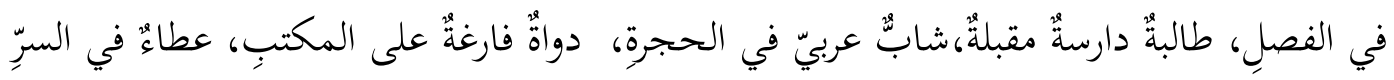

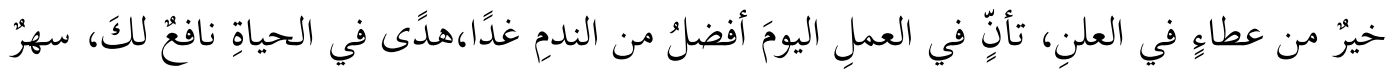

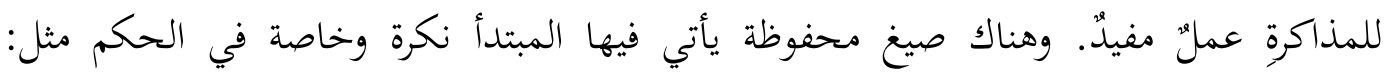

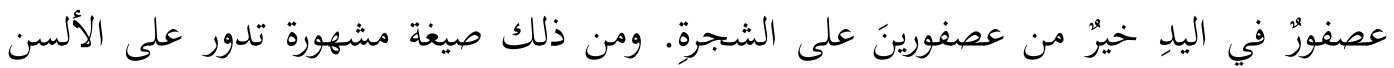
هي: سلامُ عليكمٌ (ضيف، 1986: 138).

المبتدأ على قسمين مبتدأ له خبر ومبتدأ له فاعل سد مسد الخبر فمثال الأول: زيدٌ عاذرُ

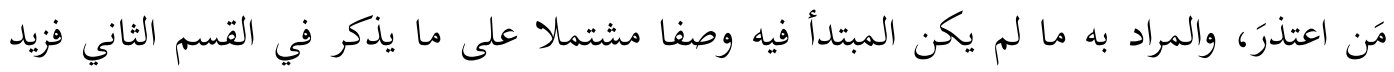

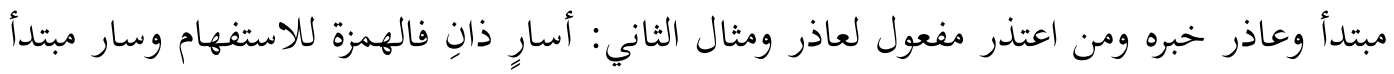

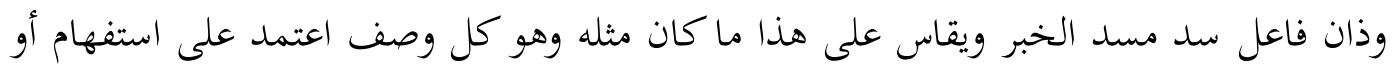

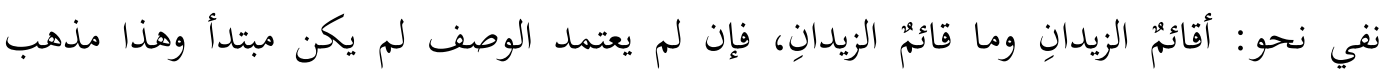

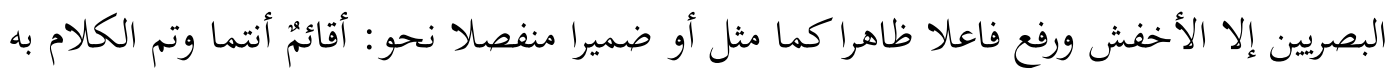


فإن لم يتم به الكلام لم يكن مبتدأ نحو: أقائمُ أبواه زيدٌ فزيد مبتدأ مؤخر وقائم خبر مقدم وأبواه

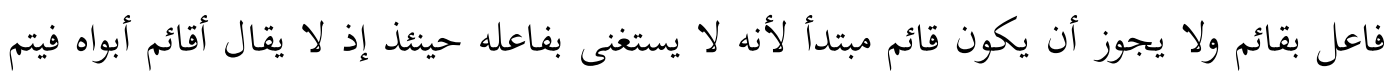

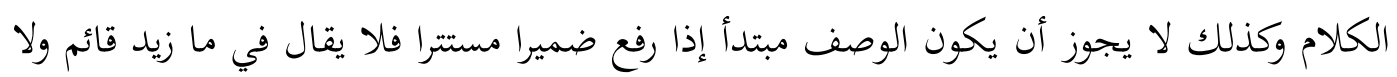

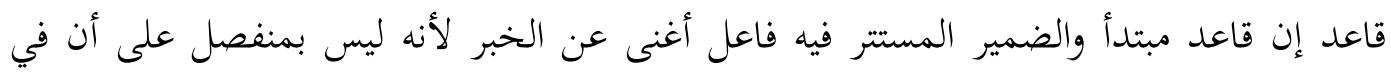

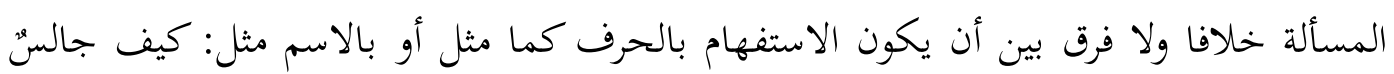

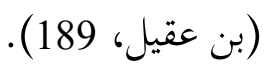

ولكتابة الورقات العلمية لا يحتاج إلى ومبتدأ له فاعل سد مسد الخبر لأنها تتم قلة

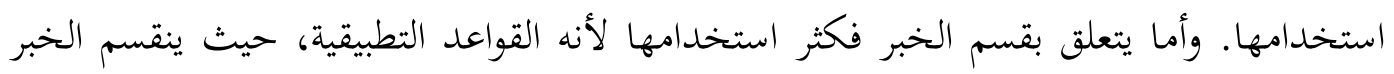

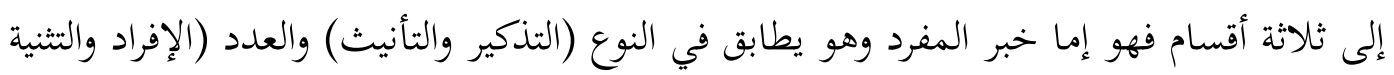

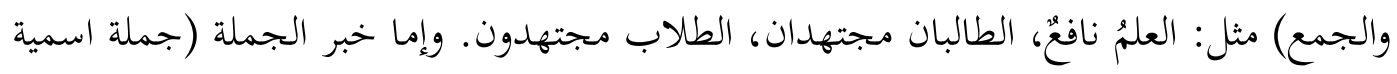

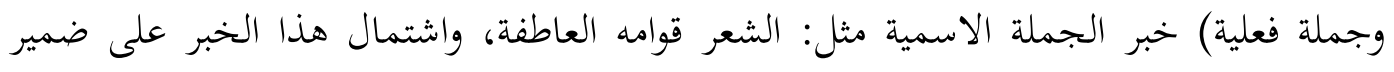

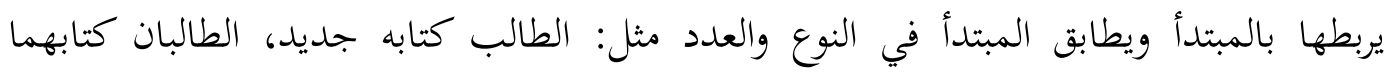

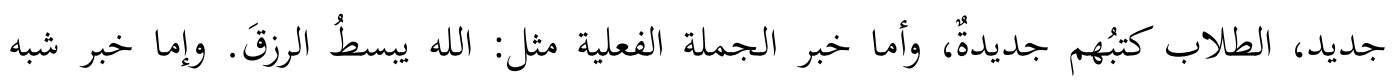

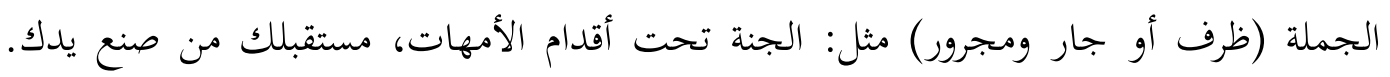

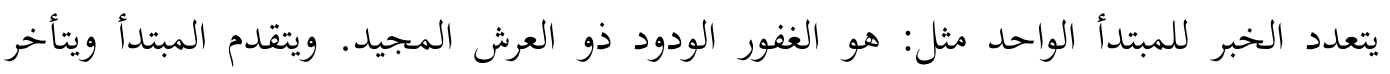

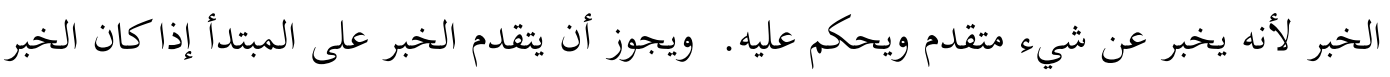

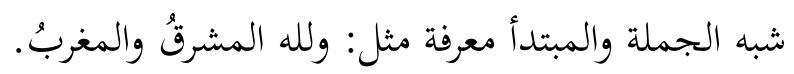

ويجب تقديم الخبر على المبتدأ في المواطن التالية: 1) أن يكون شبه الجملة والمبتدأ نكرة

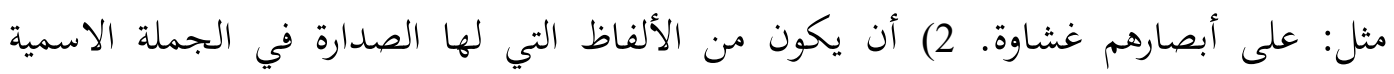

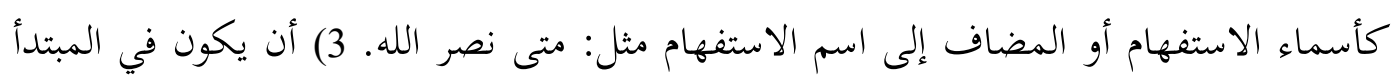

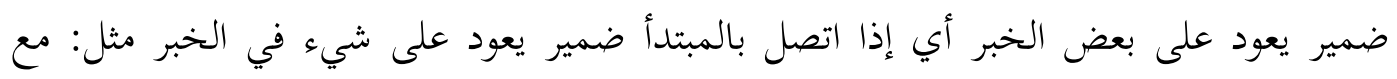
المؤمنين ربُّه. 4) أن يكون محصورا في المبتدأ مثل: ما خالق إلا اللهُ.

ويجب تقديم المبتدأ على الخبر في أربعة مواضع، هي: 1) إذا كان المبتدأ من الألفاظ

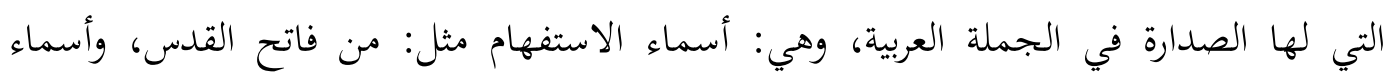

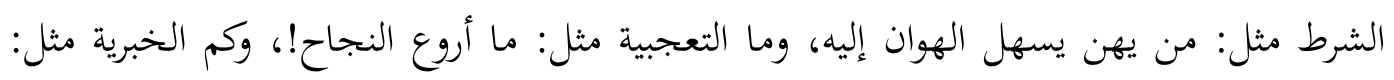

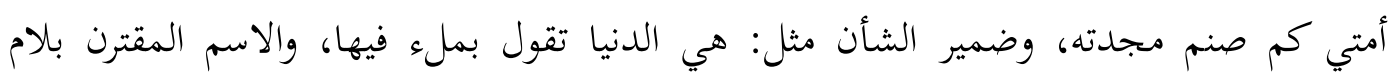


الابتداء مثل: لبيتُ تخفق الأرياح فيه، والموصول الذي اقترن خبره بالفاء مثل: الذي يتصدق فله

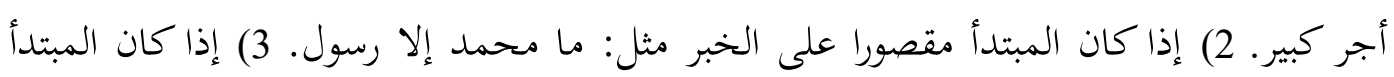

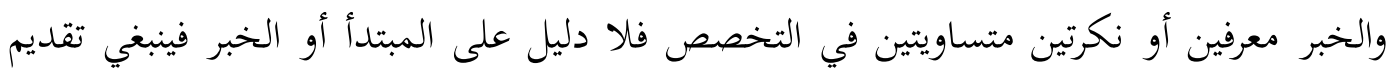

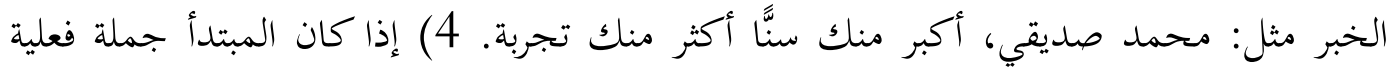

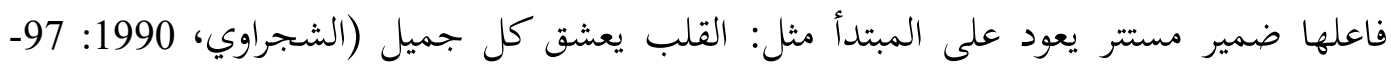

\section{الثاني، الجملة الفعلية}

الجملة الفعلية هي ماركبت من فعل وفاعل أو نائبه والمفعول به (عبد الله و الغالي). الفعل

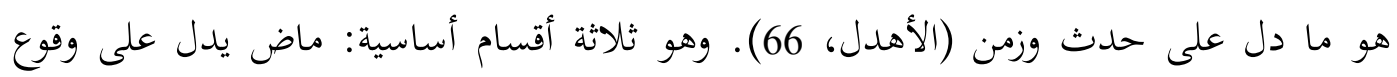

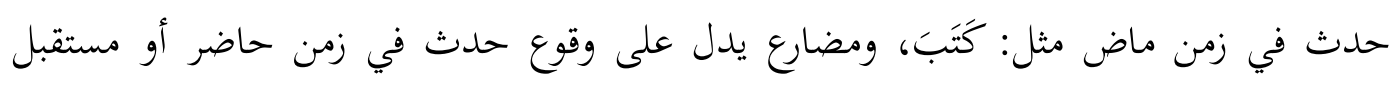

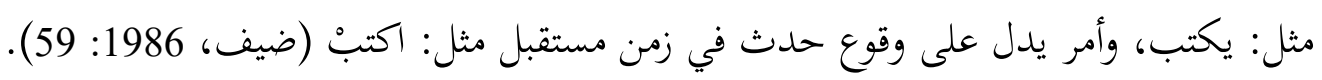

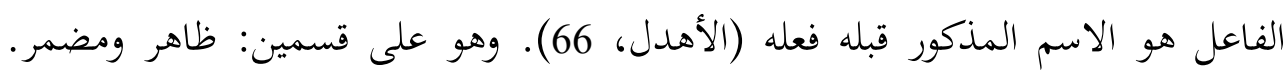

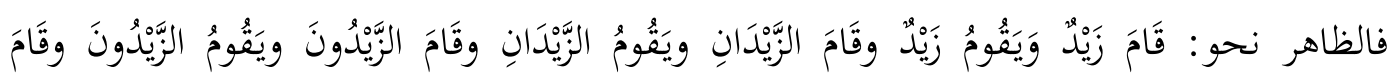

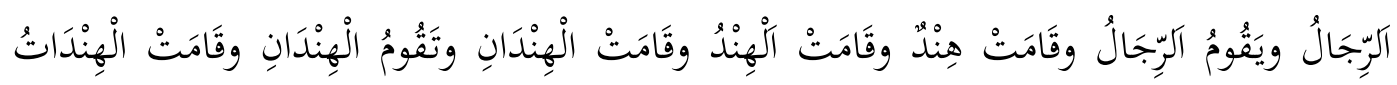

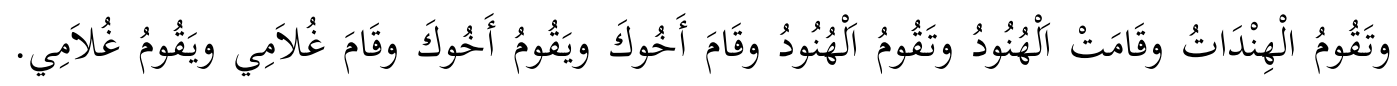

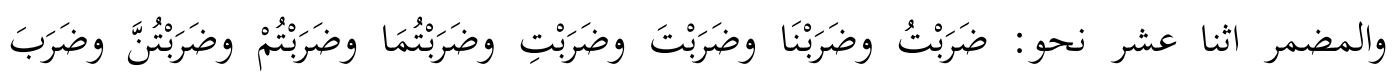

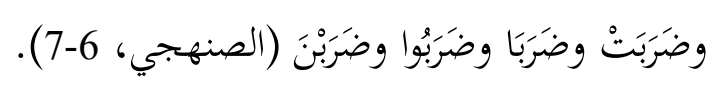

يأتي الفاعل على أوضاح وأحوال متعددة منها: يأتي الفاعل اسما صريحا مثل: إذ قال

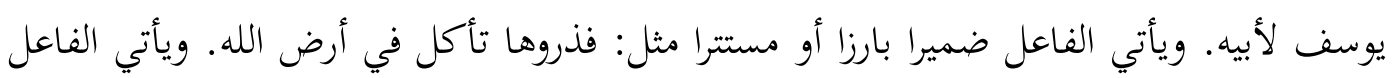

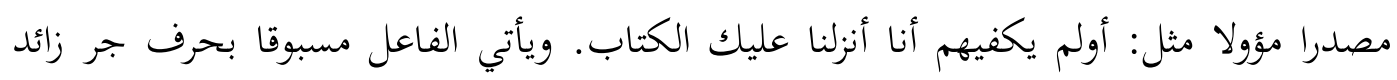
مثل: وكفى بالله شهيدا.

الأصل في الجملة الفعلية أن يذكر الفاعل بعد فعله، وإذا تقدم الفاعل على فعله تصبح

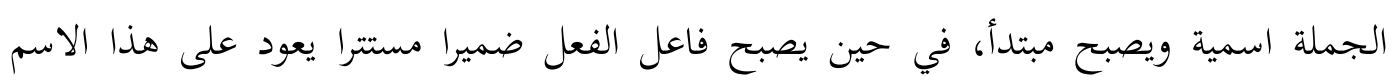

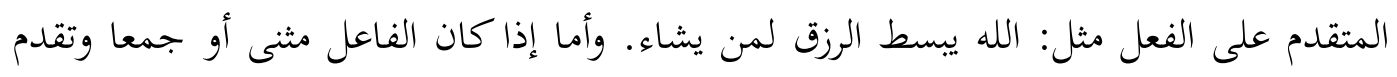

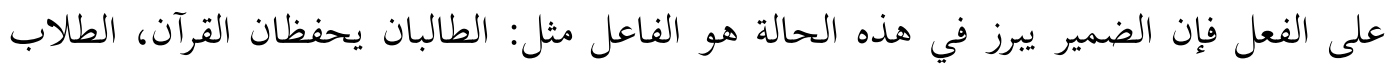


يحفظون القرآن. ويلزم الفاعل مع فعله حالة الإفراد سواء كان الفاعل مفردا أم مثنى أم جمعا مثل: قام عيسى، قام رجلان، قام المؤمنون (الشجراوي، 1990: 169-172).

وأما المفعول به هو الاسم المنصوب الذي يقع بِه الفعل مثل: ضَرَبْتُ زَيْدًا، وَرَكْبتُ الْفَرَسَ.

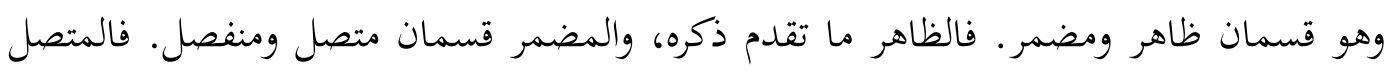

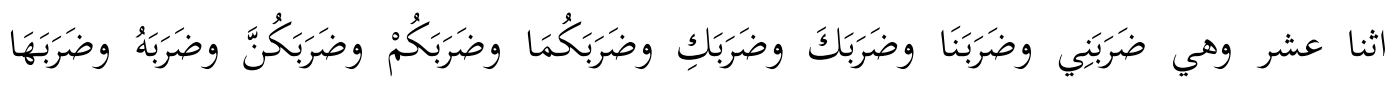

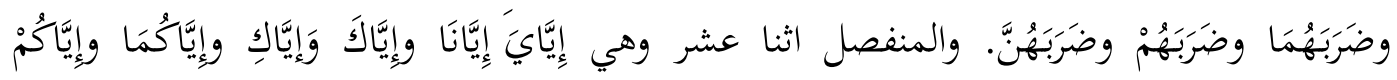

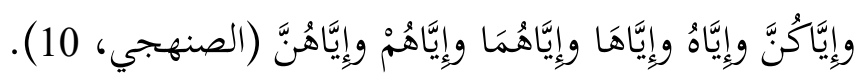

الترتيب الطبيعي للمفعول به أن يأتي بعد الفاعل، فالفعل في الجملة الفعلية يذكر أولا ثم

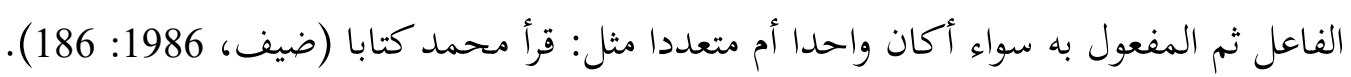

\section{ج. محاولات تيسير القواعد النحوية}

يختلف المراد بتيسير النحو في الدراسات الحديثة باختلاف مناهج الدارسين وتفكيرهم،

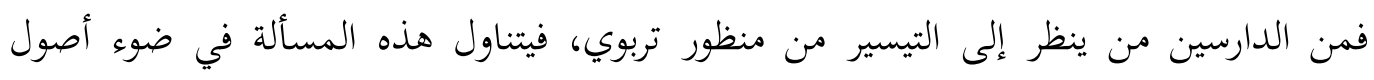

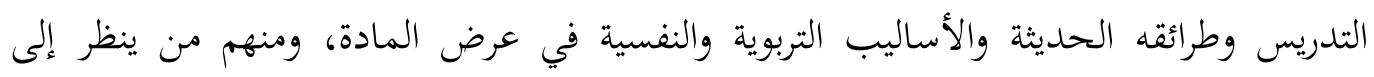

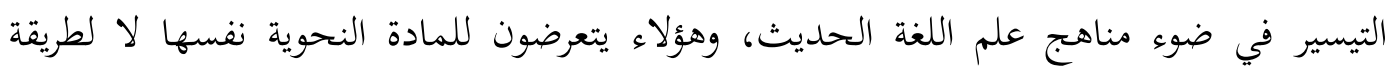

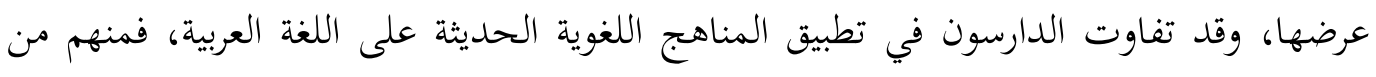

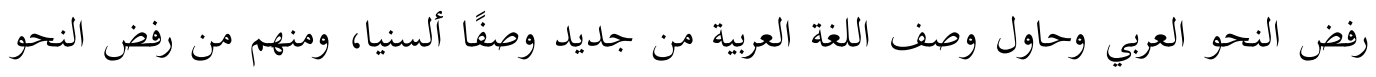

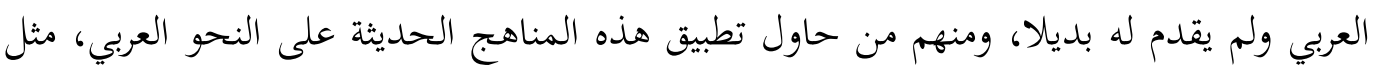

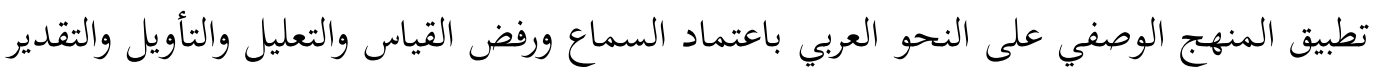

$$
\text { ونظرية العامل (عبد الله، 2010: 17). }
$$

في القواعد النحوية كثرة الافتراضات والتأويلات الناجمة والتفريعات والاختلافات

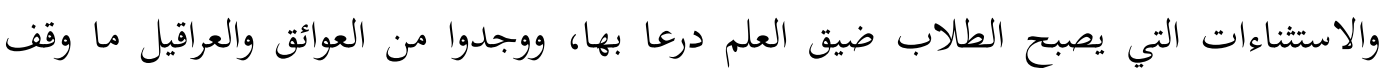

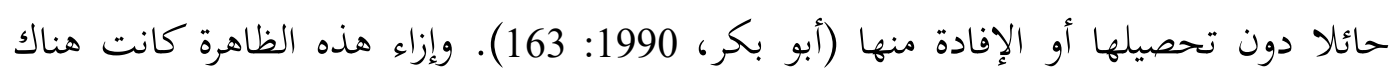

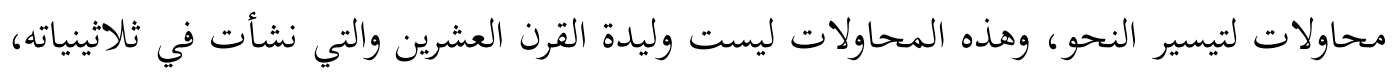

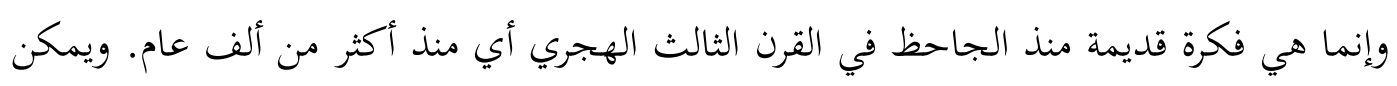

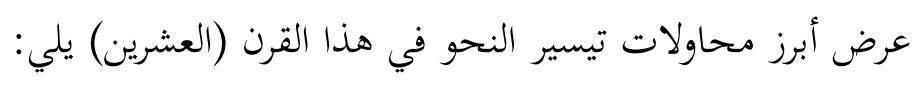


أولا، محاولة حفني ناصف وزملائه. وضع حفني ناصف وزملائه كتابهم قواعد اللغة العربية في أربعة أجزاء متخذين من الطريقة القياسية أساسا في منهج التأليف. أي أنهم كانوا يذكرون القاعدة ثم يسوقون الشواهد والأمثلة لتوضيح الحكم، وعلى الطالب أن يستوعب القواعد ويحفظ الشواهد والأمثلة.

ثانيا، محاولة إبراهيم مصطفى. ضمن إبراهيم مصتفى مقترحاته في كتابه "إحياء النحو"

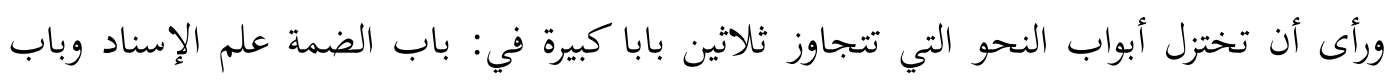

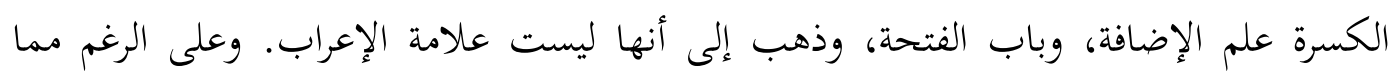
أحاط هذه المحاولة من مناقشات، فقد اتضحت منها معالم وأمور. منها: 1) الاهتمام بالقراءات القرآنية، واستقرأ الشواهد العربية من شعر ونثر. 2) استقصاء أقوال علماء اللغة الأقدمين كالخليل وسيبويه والفراء في معلجة المسائل الدقيقة في النحو، واختيار المصطلحات المناسبة لها. 3) الانتفاع بأساليب الدراسات الحديثة ومناهج البحث عند المحدثين. 4) إلغاء الأبواب غير العملية كبابي الننازع والاشتغال في جميع أبواب النحو.

ثالثا، محاولة وزارة المعارف. اتخذت محاولة التيسير الطابع الرسمي عندما قامت وزارة المعارف بتأليف لجنة للنظر في تيسير النحو، وكان ذلك بقرار من وزير المعارف عام 1938. وتشكلت هذه اللجنة من: طه حسين وأحمد أمين وإبراهيم مصتفى ومحمد أبو بكر إبراهيم، وتوصلت اللجنة إلى ثلاثة مآخذ. هي: 1) وجود فلسفة حملت القدماء على أن يفترضوا ويعللوا ويسرفوا في الافتراض والتعليل. 2) إسراف في القواعد نشأ عنه إسراف في المصطلحات. 3) إمعان في التعمق العلمي باعد بين النحو والأدب (عطا، 277-279).

رابعا، محاولة شوقي ضيف. تكرر الدعوة إلى ضرورة تصنيف جديد للمادة النحوية عام 1948 على شوقي ضيف في مدخله إلى كتاب الرد على النحاة لابن مضاء القرطوبي وكتاب تجديد النحو. وهي شبيهة بدعوة إبراهيم مصتفى من حيث إلغاء نظرية العامل ومنع التأويل والتقدير في الصيغ والعبارات وتصنيف النحو على قاعدة أحوال الكلمات لا على قاعدة العوامل.

وقد اعتمد شوقي ضيف في محاولته ستة أسس لتجديد النحو هي: الأساس الأول، إعادة تنسيق أبواب النحو، يعني حذف من أبواب النحو ثمانية عشر بابا هي باب كان وأخواتها، باب

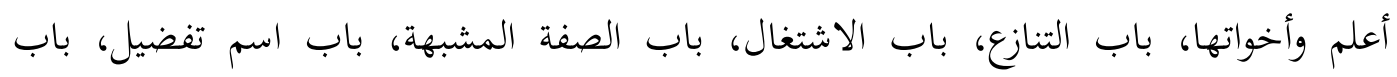
التعجب، باب أفعال المدح والذم، كنايات العدد، الاختصاص (واكتفى بإعراب هذه الصيغ 
الست في باب التمييز)، باب التخذير، الاغراء، باب الترقيم، الاستغاثة، الندبة. والأساس الثاني،

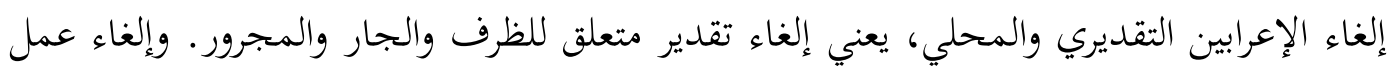

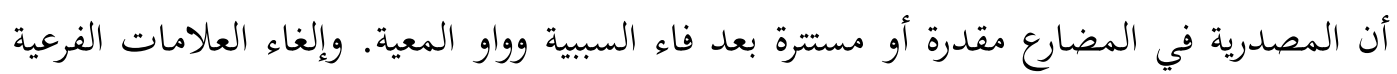
في الإعراب.

والأساس الثالث، الإعراب لصحة النطق. إن الإعراب ليس غاية في ذاته بل هو وسيلة

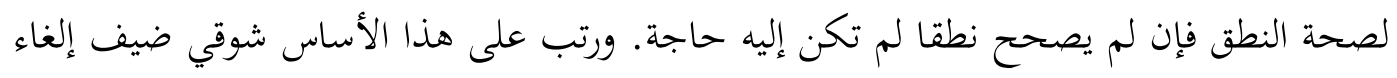

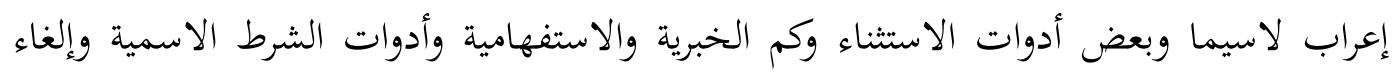

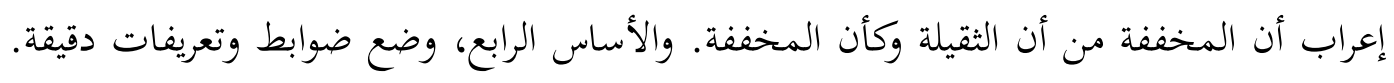

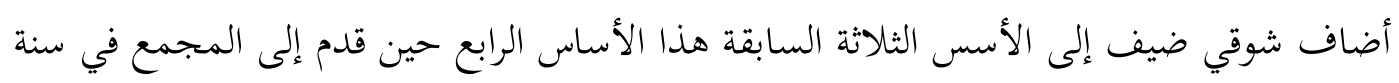

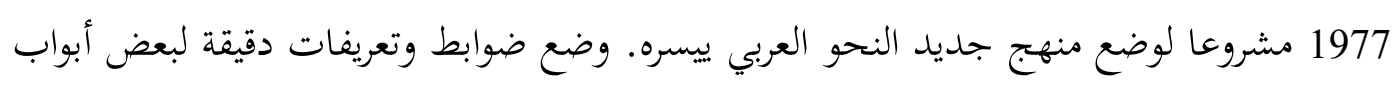

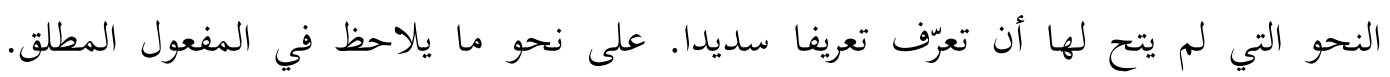

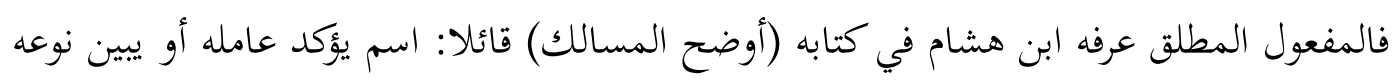

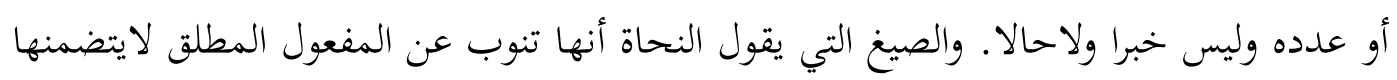

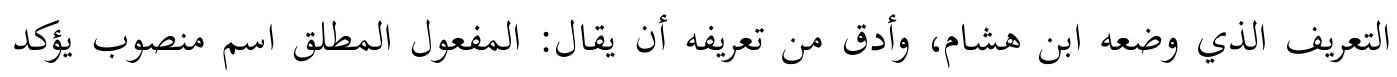

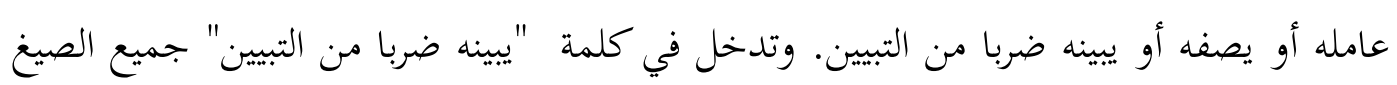

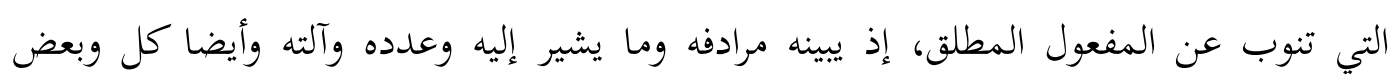
المعربتان عن جميعه أو شطر منه.

والأساس الخامس، حذف زوائد كثيرة. في مباحث تقسيمات الاسم وأبنيته حذف شوقي

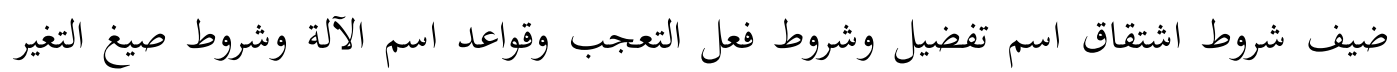
وقواعده العسرة وحذف قواعد النسب المعقدة. وفي قسم المرفوعات حذف من من باب المبل المبتدأ

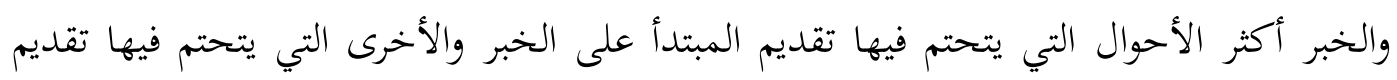

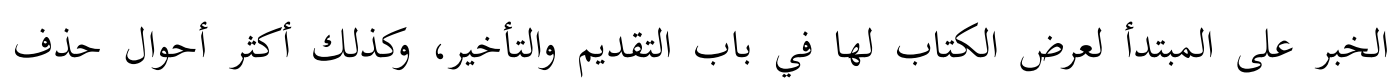

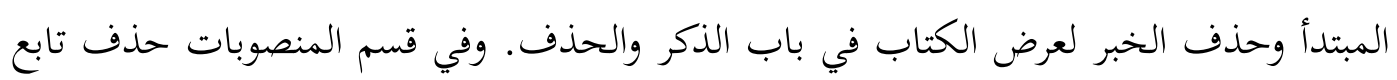

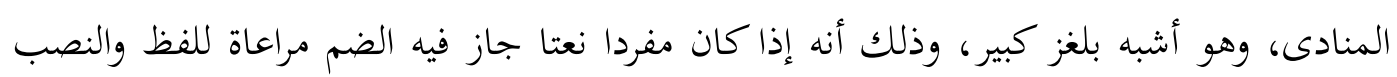
مراعاة للمحل. 
والأساس السادس، إضافة متنوعة. وضع شوقي ضيف في قسم الأول من قواعد ضرورية

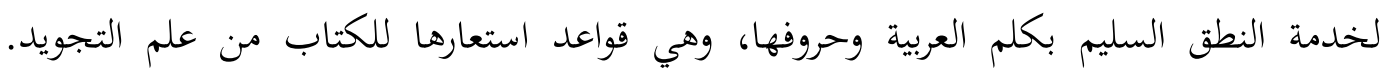

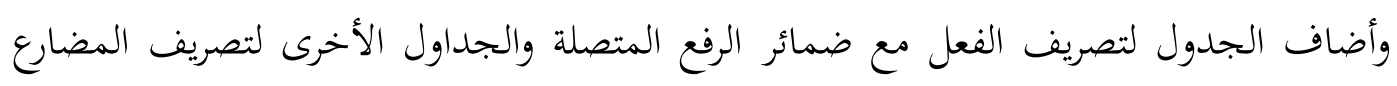

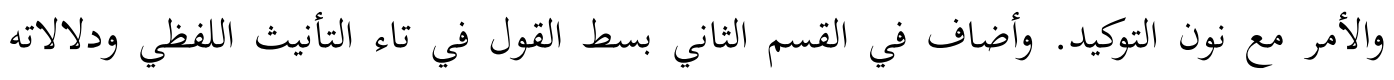

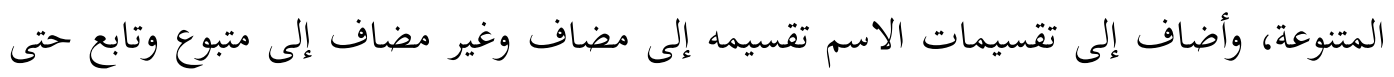

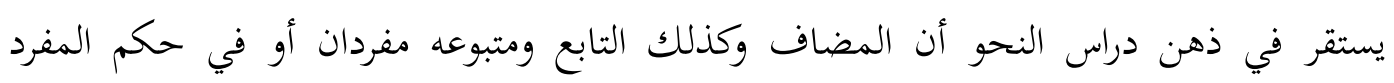
لاجمل مستقلة (السيد، 467-478).

\section{د. طرق تعليم القواعد النحوية}

الطريقة هي عبارة عن خطة عامة لاختيار وتنظيم وعرض المادة اللغوية (الناقة، 2003: 46). نظرا لأهمية القواعد وصعوبتها فإن التخصصين والمهتمين بطرائق التعليم وضعوا طرائق كثيرة لتعليمها. وذلك لتذليل قسم من الصعوبات وحالة الجفاف التي تتصف بها لتها القواعد النحوية.

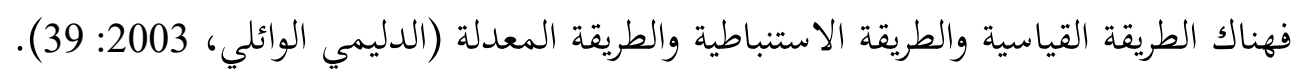
الأول، الطريقة القياسية

هذه الطريقة تسمى بالطريقة الاستنتاجية، وهي التي تبدأ بعرض القاعدة النحوية ثم بتقديم

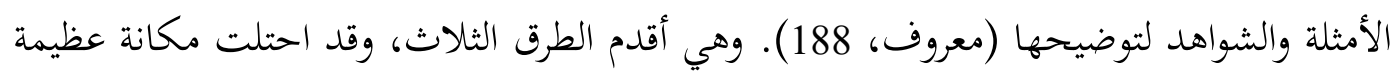

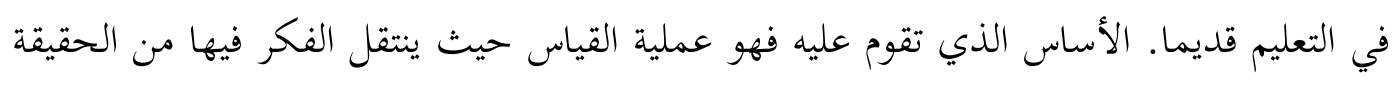

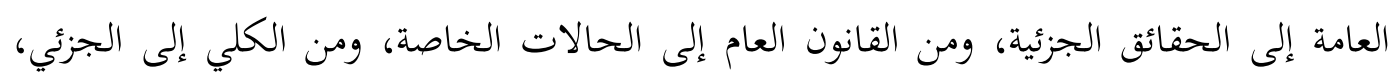

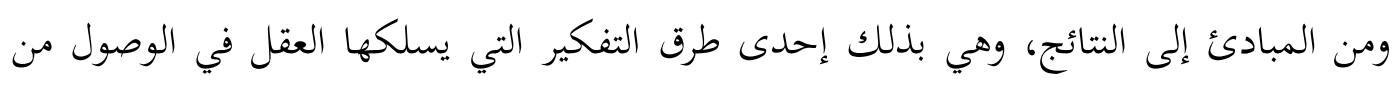

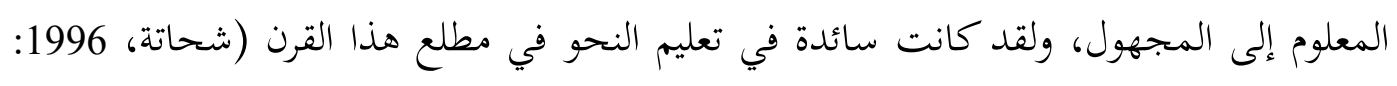

تقوم هذه الطريقة على الخطوات التالية: التمهيد، وعرض القاعدة، وتحليل القاعدة، والتطبيق (الدليمي والوائلي، 50).

1. التمهيد. هو عملية ضرورية ومهمة جدا في أي عمل يريد القيام به. وفي تعليم النحو

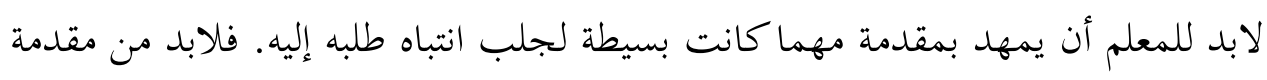

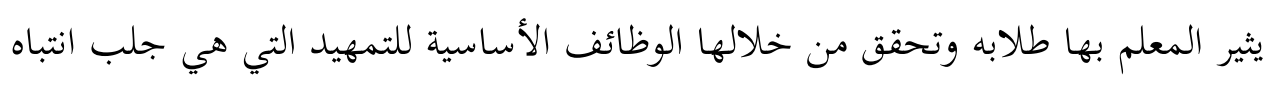

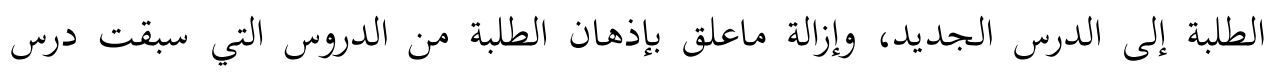


النحو. وهذا لايعنى محو المعلومات عن تلك الدرس وإنما يعني تعطيل التفكير بها لكي

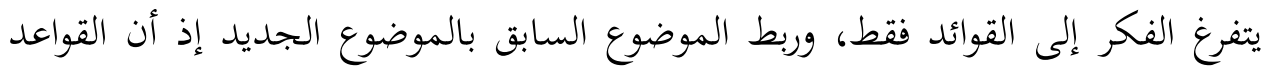

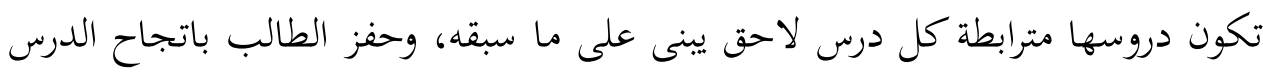

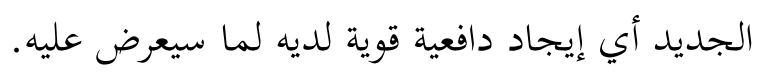

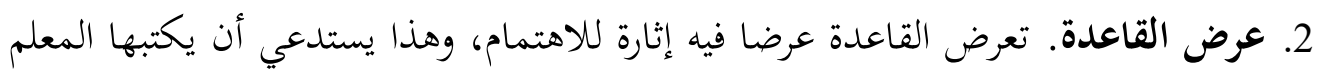
بخط جميل في مكان بارز من السبورة، بحيث تقع القاعدة في مستوى نظر الجميع.

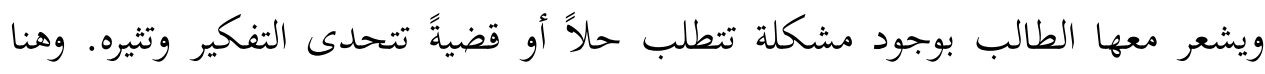

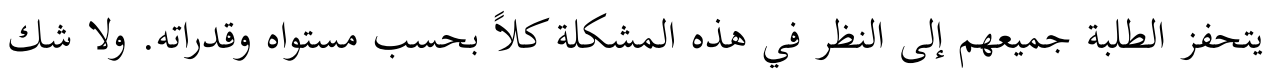

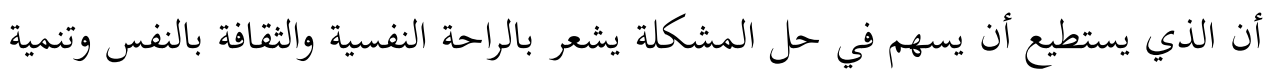
الجرأة لاصدار الأحكام مستقبلا.

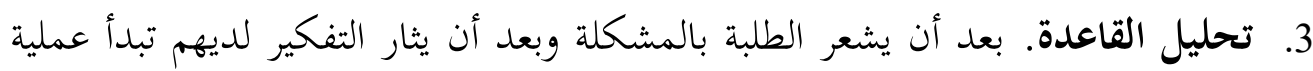

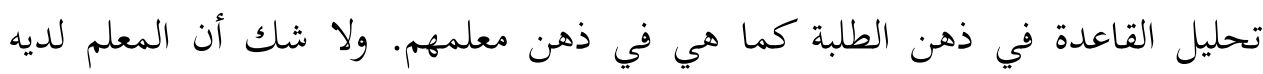

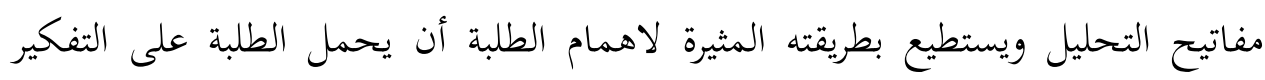

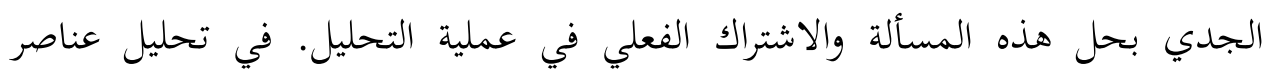
القاعدة يبدأ المعلم بأن يضع أسئلة لها علاقة مباشرة بموضوع القاعدة أو يعطي مثالا

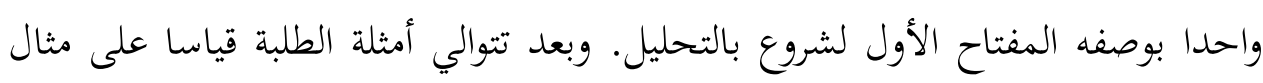
المعلم واستجابة لما أثناره من أسئلة.

ومن الخطأ الاعتقاد أن القياسية تعني أن يكون المعلم هو المحور الأساسي فيها فيهمل

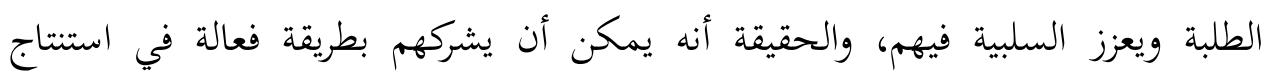

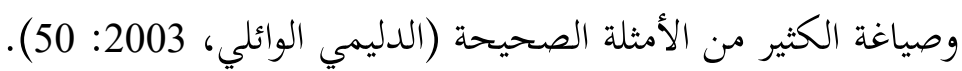

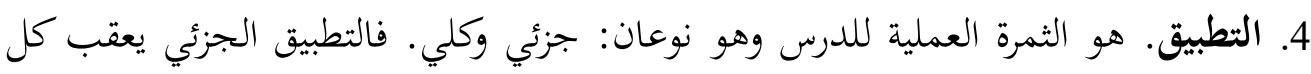

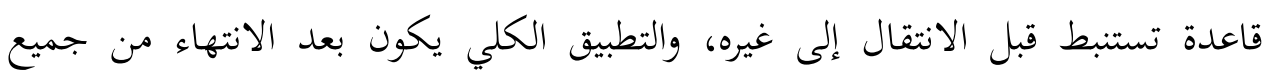
القواعد التي يشملها الدرس ويدور حول هذه القاعدة جميعا. ونوع التطبيق الآخر:

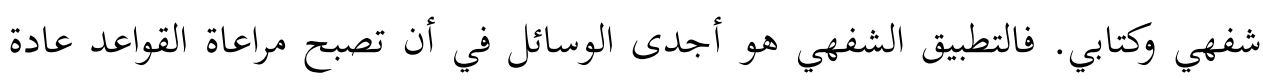

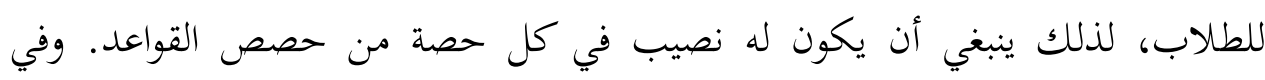

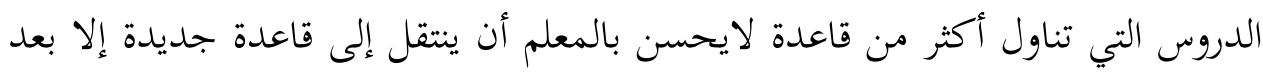
أن يطبق على القاعدة السابقة تطبيقات كافية. 
ومن المستحسن أن يطالع الطلاب أحيانا قطعة متصلة لتطبيق القواعد عليها، ويُعنى في

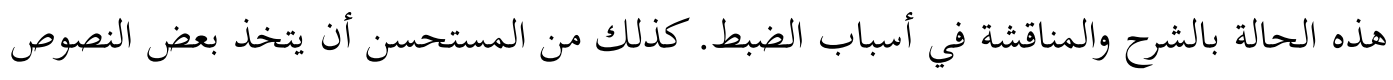

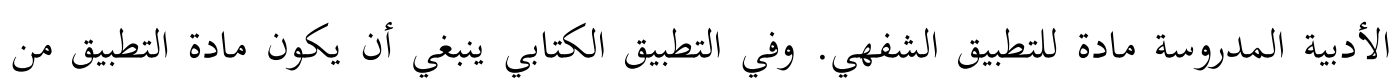

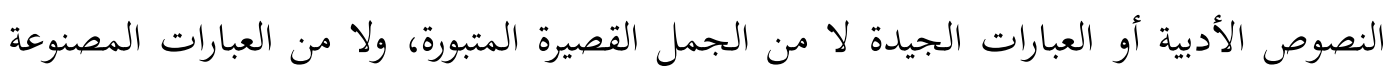
ليتمرس الطلاب بجمال العبارات بجانب صحة التراكيب.

وينبغي أن تتجه أسئلة التطبيق اتجاها عمليا يعين بطريقة مباشرة على تحقيق الغاية

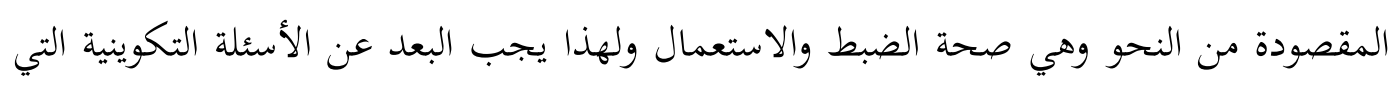

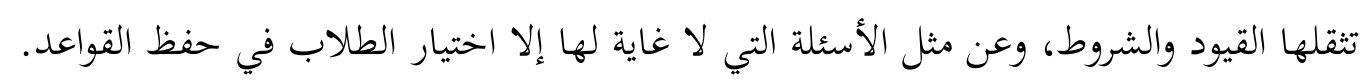

هذا ويحسن أن يستقل الطلاب بحل التمرينات الكتابية دون اشترك أو مساعدة المعلم. وبعد تصحيح الكراسات يعود المعلم بالطلاب إلى شرح الأسئلة ليستطيعوا تصويب أخطائهم.

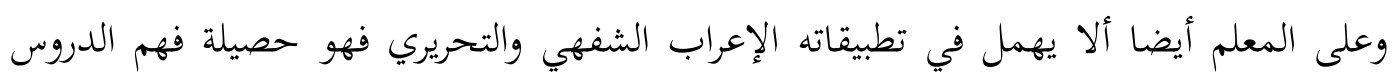

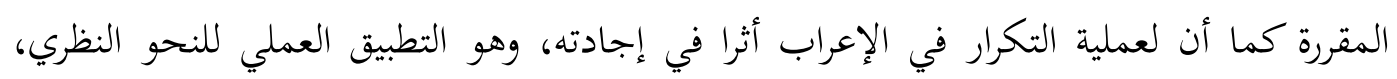

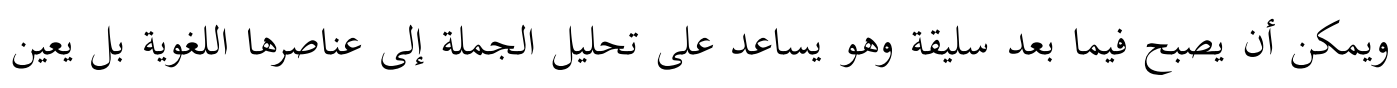

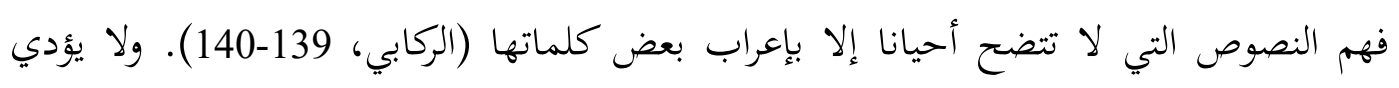

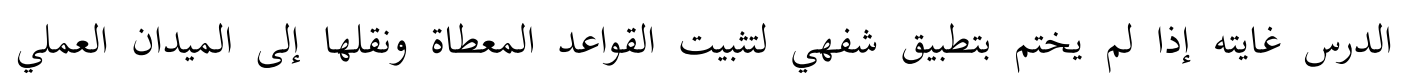
(الركابي، 139-140).

التطبيق وفقا لهذه الطريقة يسأل المعلم عن بعض أجزاء القاعدة بوصفها الأساس الذي بدأ

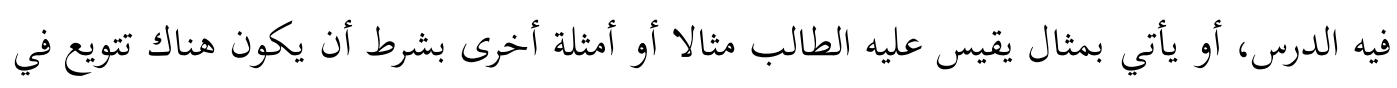

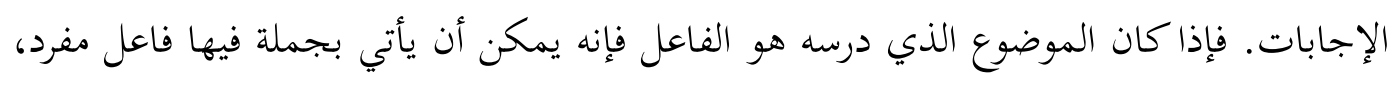

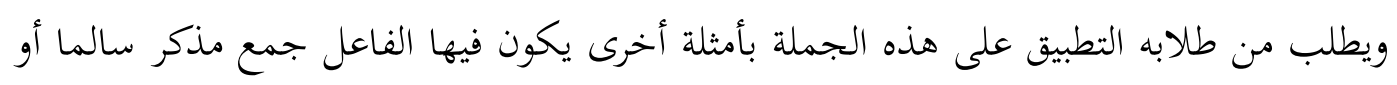

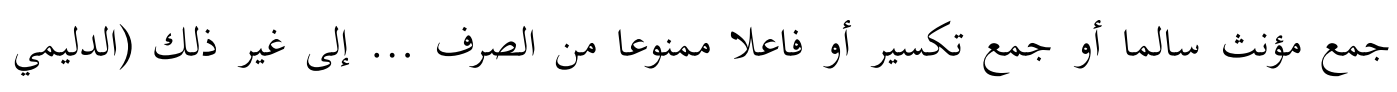
والوائلي، 51).

إن لكل طريقة أنصارا وخصوما، وأنصارها يعتبرها أفضل الطرق، وخصومها يرون أنها

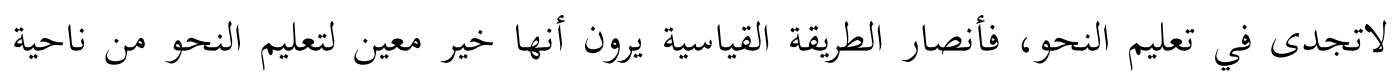

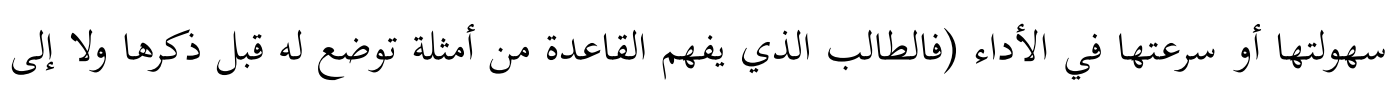
سبيل حفظها حفظا يعين على تذكرها) (شحاتة، 209). 
ويقول السيد أن يرى أنصار من هذه الطريقة أنها سهلة وسريعة في الأداء وتؤدي إلى

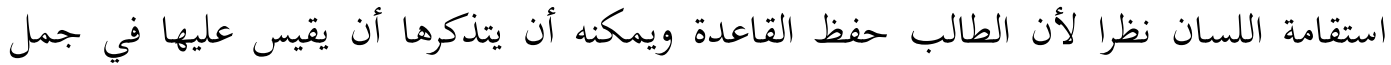
جديدة.

وأما معارضو هذه الطريقة فيرون أنها ضارة وغير مفيدة لأنها: 1) تبعث في الطلبة الميل إلى الحفظ وتعوده المحاكاة العمياء والاعتماد على غيره، وتضعف فيه قوة الابتكار في الأراء

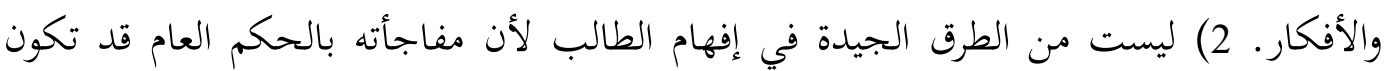

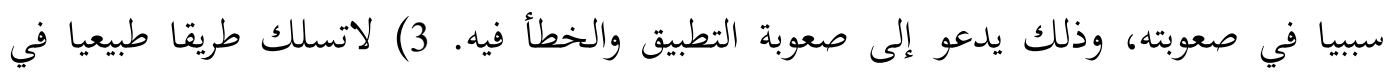

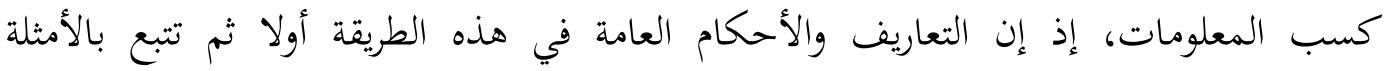
والجزئيات خلافا لطريقة العقل في الوصول إلى ادراك الأمور الكلية بعد مشاهدة جزئياتها. تعمد إلى تقديم القاعدة والتعريف على الأمثلة والتطبيقات، وهذا بمثابة تقديم الصعب على على السهل السهل

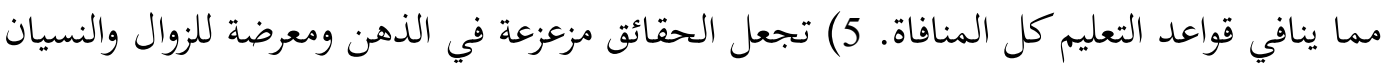

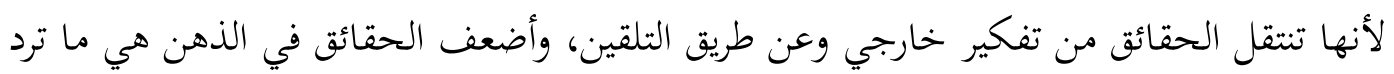

$$
\text { إليه عن هذا الطريق (السيد، 480). }
$$

ويقول الصميلي أن من عيوب هذه الطريقة السرد الذي يقدمه المعلم كشرح للقاعدة المعلنة، لأن الطالب يكون في حالة المتلقي الذي يصغي، وقد يشرد ذهنه عن الدئ الدرس إلى أفكار

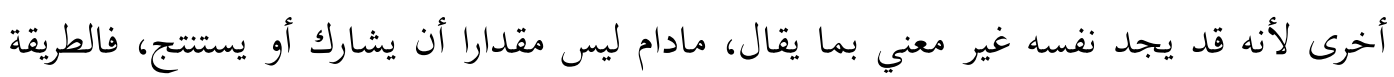

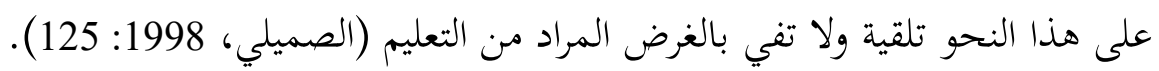

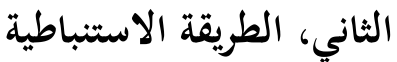

هذه الطريقة تسمى بالطريقة الاستقرائية، ونشأت مع مَقْدَم أعضاء البعثات التعليمية من

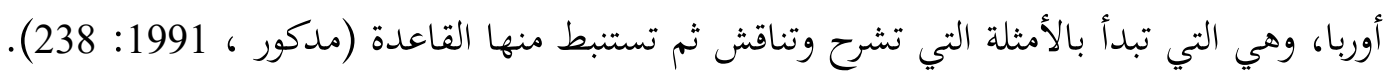

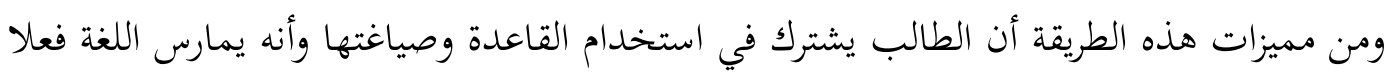

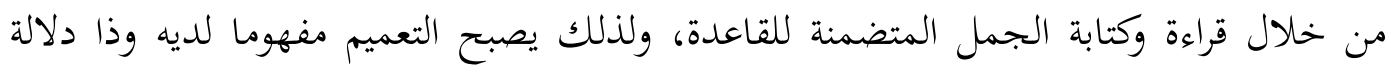
(الناقة، 241).

تقوم هذه الطريقة على طريقة هربارت ذات المراحل الخمس: التمهيد، والعرض، والربط

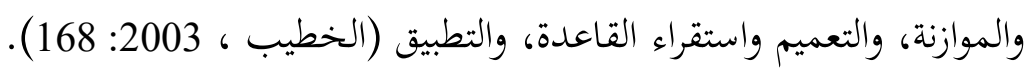


1. التمهيد. هو عملية تحليلية لما في عقول الطلاب من معلومات سابقة، لها صلة بالدرس الجديد بتعرف إليها المعلم، ثم يرتبها ترتيبا يتناسب والدرس الجديد لتكون أساسا له، وتكون مع بعضها وحدة عملية. كذلك فإن الهدف الخاص من الدرس يثبت في هذه المرحلة، ويربط بحاجات الطلاب ليستثير هذا الهدف رغبتهم بالمادة الجديدة، فيكون الدافع إلى الدرس قائما في الدقائق الأولى من ساعة الدرس، ويكون إيقافهم على الموضوع الجديد حاملا لهم على اتخاذهم موقفا إيجابيا للتعلم، يسبب توفر شرطيه الأساسين: المشكلة والدافع. كذلك فإن تحديد الهدف الخاص من الدرس في المرحلة الأولى يعين المعلم على تحديد اتجاهه في ساعة الدرس فيتجه كليا لانجازه.

ويجمل بالمعلم ألاّ يطيل هذه المرحلة أكثر من خمس دقائق، توجز بأسئلة جذابة مثيرة لمعلومتهم القديمة، أو مثيرة لموضوع حيوي له صلة بالقاعدة الجديدة، أو يذكر ملخص موجز للدرس المنصرف له صلة بالموضوع الجديد بطريقة تثير الانتباه إليه، ولا مانع من أن يذكّر الطلاب كذلك في عرض الدرس بالهدف منه لتنبيهُم إليه، لذا كان ضروريا كتابة (اسم الموضوع) على السبورة، وبقاؤه الدرس كله.

2. العرض. هي عملية جميع الحقائق الجزئية من الطلاب على أن تكون منوعة موضوعا وشكلا، كما يجب أن يكون اختيار هذه الحقائق بما يسر لهم ادراك القاعدة، ولا يعقدها ولا يربكها كأن تكون خالية من الشواذ وتكون خالية من الاضطراب والتعقيد في التركيب، وأن تكون واضحة المعنى مقبولة في وسط الطلاب غير باعثة على النقد أو النفور أو الايهام - وكل ذلك لغرض استباط العلاقة المنطقية بينها وبين القاعدة الشكيلة المراد استنتاجها بيسر وسهولة وقصر وقت. وعلى المعلم أن يفيد غاية القاعدة من السبورة بعرض

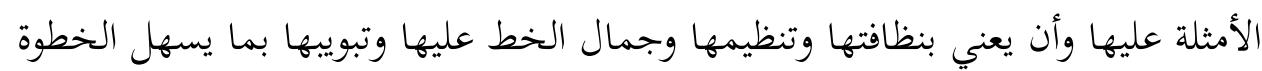
التالية. 3. الربط والموازنة. على المعلم أن يعني بالاشتراك مع الطلاب بالربط والموازنة بين الأمثلة المنظمة على السبورة حتى يقفوا على المتشابه ثم المتباين، وبذا يسهل عليهم ادراك العلاقات بين الأمثلة، ثم يتجه العقل إلى افتراض تعميم وقاعدة تفسربه هذه العلاقات بين الأمثلة، وهذا الافتراض يحتاج إلى استدلال وتفكير كما يحتاج تخيل وابتكار . وكل ذلك يحتاج إلى إناة وترو وعدم استعجال باصدار التعميم. وعلى المعلم أن يعود طلابه على 
ضرورة الإناة وجمع الأدلة المنطقية قبل الحكم، كما عليه أن يعني بتنظيم السبورة وجمال الخط لأن ذلك يعين الطلاب على الفهم.

4. التعميم واستقراء القاعدة. هي ميل العقل إلى أن ينتزع من العلاقات بين الأمثلة أحكاما

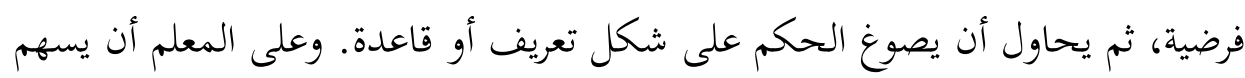

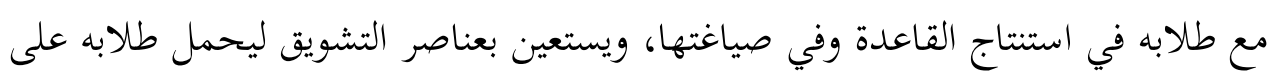

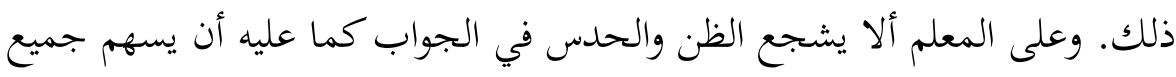

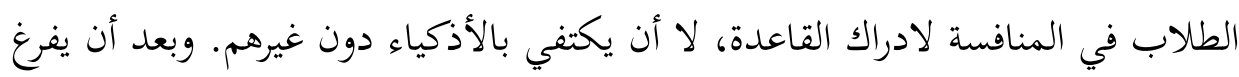

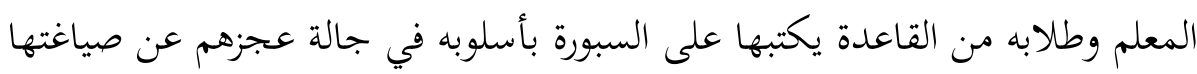

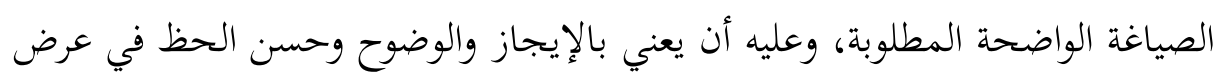

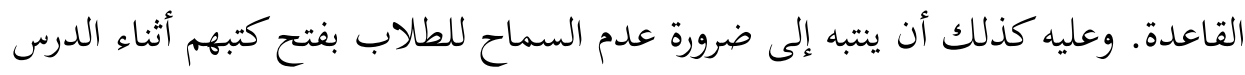

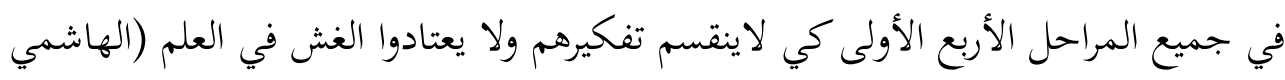
(218-214: 1983،

5. التطبيق. يعد التطبيق من أصعب الخطوات على الطالب لأنه عملية فكرية تسبقها عملية

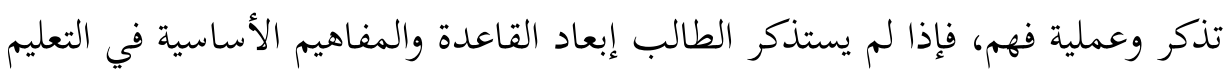

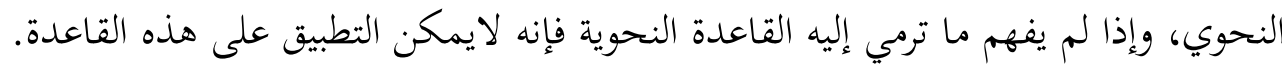

وعلى هذا الأساس فإن على المعلم في خطوة التطبيق أن يذكر أمثلة تطبيقية

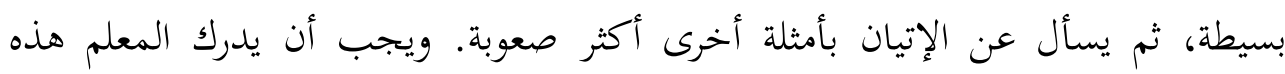

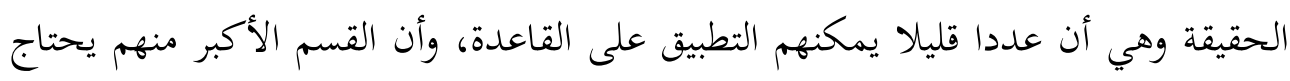
إلى وقت أطول وجهة أكثر لممارسة عملية التطبيق.

في هذه الخطوة يمكن الطلبة أن يفحصوا صحة التعميم أو صحة القاعدة التي توصولوا إليها وذلك بالتطبيق على أمثلة وجزئية أخرى (الدليمي والوائلي، 42).

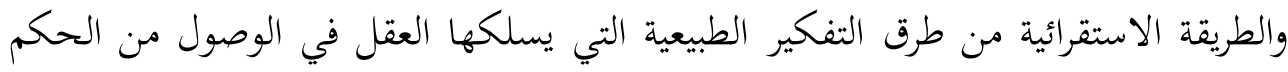

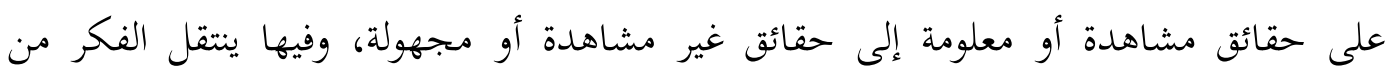

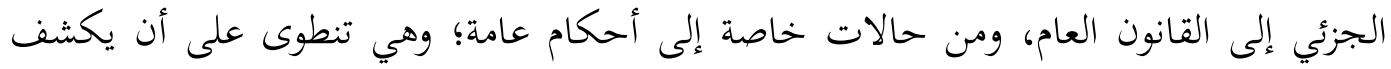

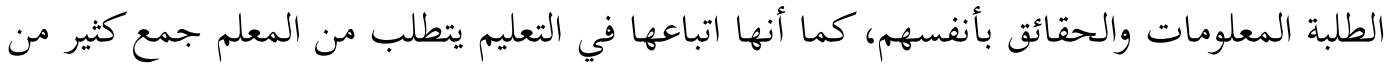

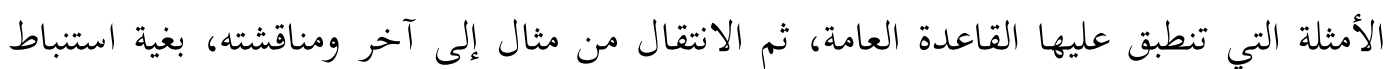
القاعدة العامة، فيعبر عنها الطلبة بأنفسهم. 
ويرى أنصار هذه الطريقة : أن في طريقته خير معين لتحقيق أهداف النحو لأنها: 1) تهيج في الطلبة قوة التفكير، وتأخذ بأيديهم قليلا قليلا حتى يصلوا إلى الحقيقة. 2) طريقة جادة في التربية لأنها توصل إلى الحكم العام تدرجيا، وذلك يجعل معناه واضحا جليا فيصير التطبيق عليه سهالا. 3) تحرك الدوافع النفسية لدى الطالب فيهتم اهتماما بالغا فيتنبه ويفكر ويعمل 4) تقوم على عرض الأمثلة الكثيرة المتنوعة التي تدور حول الحقائق الملموسة، وتتخذ الأساليب والتراكيب أساسا لفهم القاعدة، وتلك هي الطريقة الطبيعية لأنها تمزج القواعد بالأساليب. ويرى معارضو هذه الطريقة أنها تتسم: 1) البطء في إيصال المعلومات إلى أذهان الطلبة، والاكتفاء أحيانا بمثال أو مثالين أو ثلاثة لاستنباط القاعدة، وفي هذا من التفريط ما يجعلها غير سليمة. 2) أنها تختار أمثلتها لاتصل بينها صلة فكرية ولا لفظية، إنما هي جمل مبتورة في موضوعات مختلفة ليس فيها خاصة لغوية، إلا أنها تحمل تمثيلا لقاعدة خاصة، وأما أنها تشرح فكرة من الأفكار التي تمتلئ بها عقول الناس، وأما أنها ترتبط برباط لفظي من أدوات الربط الكثيرة في اللغة العربية، فذلك كله وغيره مما تخلو منه هذه الأمثلة، وهي لاترمي إلى غاية تعبيرية خاصة ولا تثير في نفس الطلبة شوقا إليها ولا إلى القاعدة التي سيدرسونها في ظلالها، مع أن كل درس اللغة العربية ترمي في نهاية أمرها جميعا إلى شيئين: الفهم والإفهام، وكل ماتقدم في هذه الدروس وسيلة إليهما، وهي تستخدم التطبيق بشكل تعجيز للطلاب، مع أن المفروض فيه طبع الأساليب السليمة التي تحوي من خصائص اللغة ماهو فطري بعيد عن التكلف. 3) إن استنباط القاعدة من أملثة معينة لاخيرا فيها ولا غناء، وهي عملية ثبت أنها مستحيلة وليس لها أصل عملي ولا وجه للمقارنة بين اللغة والعلوم الطبيعية في الاستباط لأن التجربة في العلوم الطبيعية ثابتة مطردة يمكن استخلاص قوانين عامة منها ولكن هذا لاينطبق على اللغات (السيد، 484-484).

\section{الثالث، طريقة المعدلة}

وهي أحدث الطرق الثلاث من جهة الترتيب التاريخي وقد نشأت نتيجة تعديل في طريقة التعليم السابقة ولذا تسمى بالطريقة المعدلة، وهي تقوم على تعليم القواعد النحوية من خلال الأساليب المتصلة، لا الأساليب المنقطعة. ويراد بالأساليب المتصلة قطعة من القراءة في موضوع واحد، أو نص من النصوص يقرؤه الطلاب ويفهمون معناه ثم يشار إلى الجمل وما فيها من الخصائص ويعقب ذلك استنباط القاعدة منها وأخيرا تأتي مرحلة التطبيق. ومن الصور التي أخذتها هذه الطريقة معالجة بعض أبواب منهج النحو بطريقة التطبيق العملي دون حاجة إلى شرح قواعدها، أما ما عداها من الأبواب فيجب أن يدرس على الطريقة الاستنباطية، ولكن ليس في ظل هذه الأمثلة المتكلفة المبتورة التي تنتزع من أودية مختلفة 
لايجمع شتاتها جامع، ولا تمثل معنى يشعر الطالب أنه في حاجاة إليه، بل يجب أن تدرس في

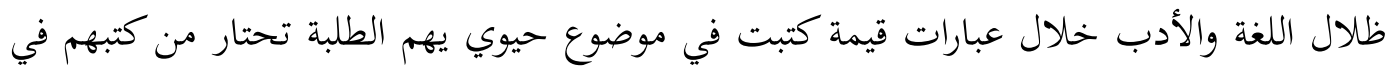

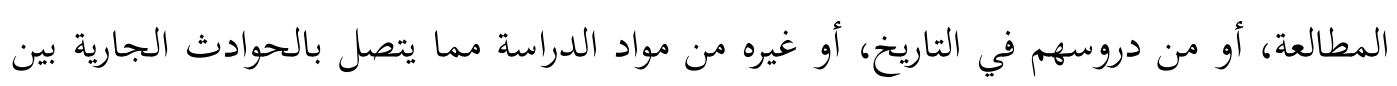

$$
\text { سمعهم وبصرهم (شحاتة، 212). }
$$

وتقوم هذه الطريقة على الخطوات التالية: التمهيد، وكتابة النص، وتحليل النص، واستنتاج

$$
\text { القاعدة، والتطبيق (الدليمي والوائلي، 59). }
$$

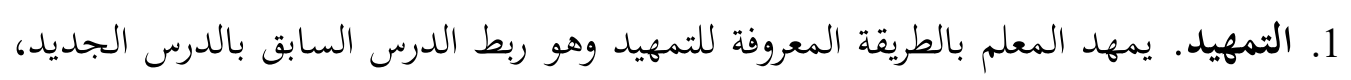

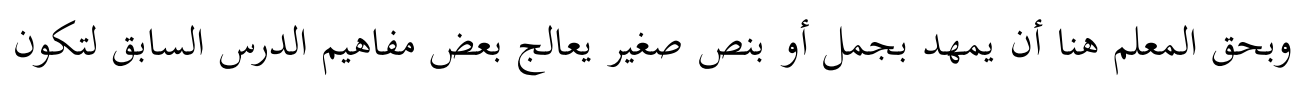

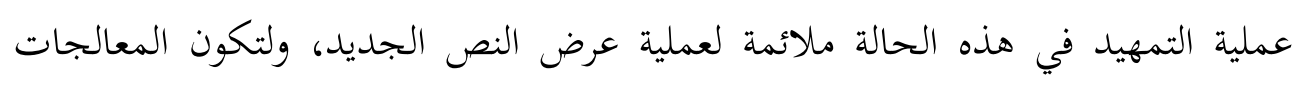
بنصوص مختارة منذ بداية الدرس وليس بجمل مبثورة.

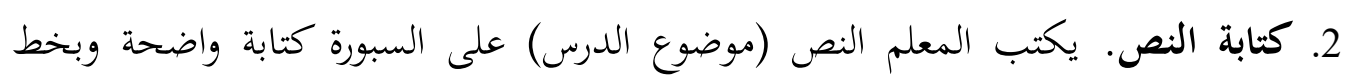

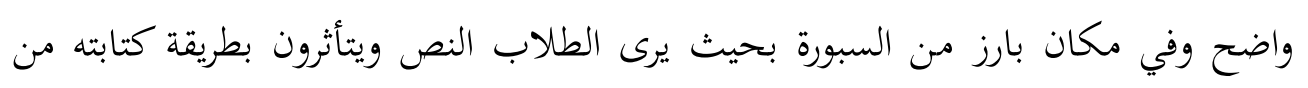
حيث الخط والتلوين واتباع وسائل إيضاح أخرى.

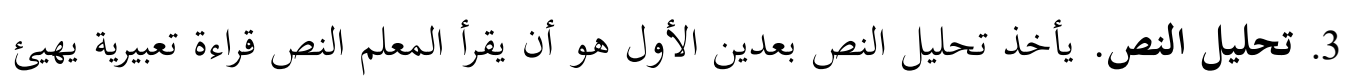

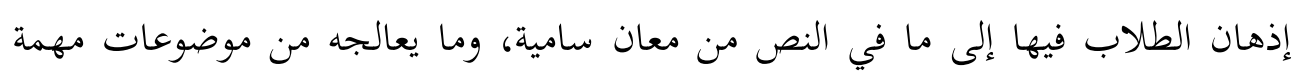

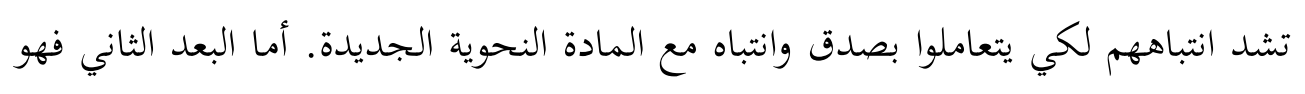

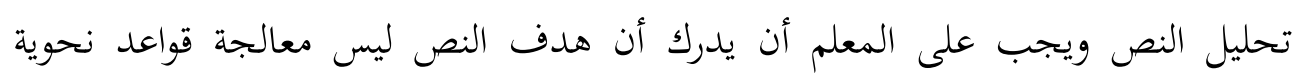

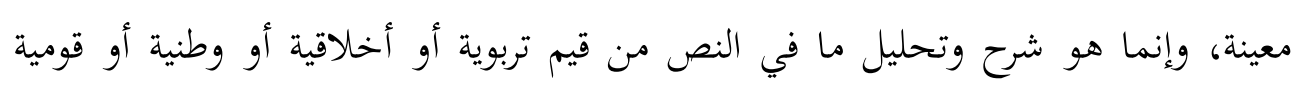

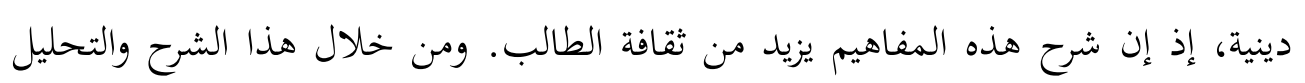

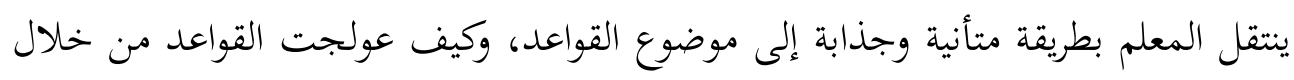

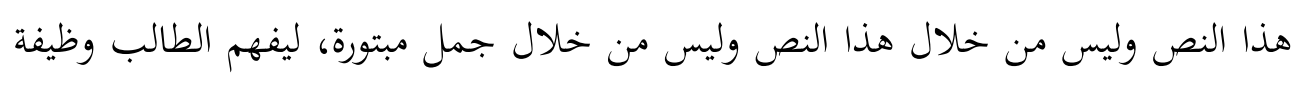

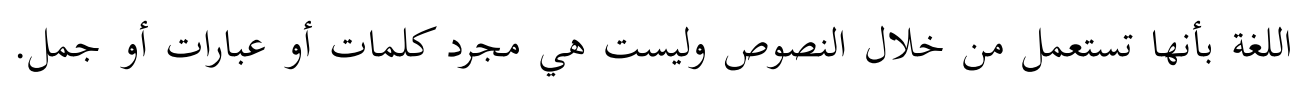

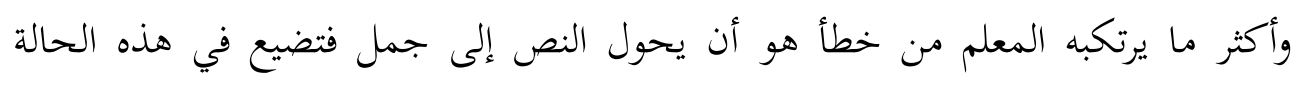
الأهداف الأساسية من النص.

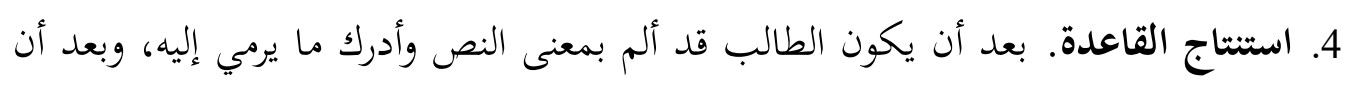

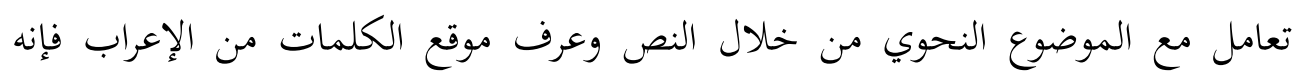

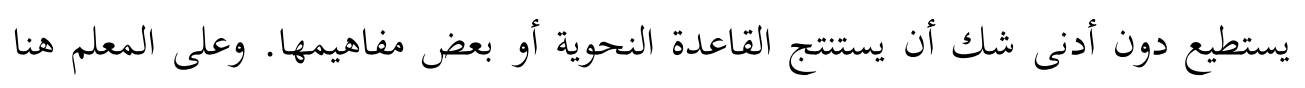

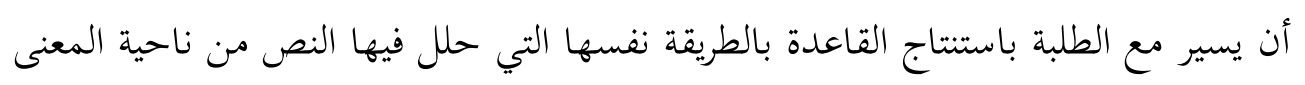


والقواعد. وهنا يشعر الطالب بأهمية القواعد في سياق اللغة عامة، فيميل إلى حبها والتعامل معها بشفافية.

5. التطبيق. التطبيق على القاعدة النحوية قد لا يكون يسيرا لعدد كبير من الطلبة، ومع ذلك فإن المعلم يمكنه أن يسأل بطريقة ليست بعيدة عن هذا الأسلوب (أسلوب النص) ليشجع طلابه على التطبيق على القاعدة النحوية، كأن يأتي بنص آخر يتضمن بعض أبعاد القاعدة

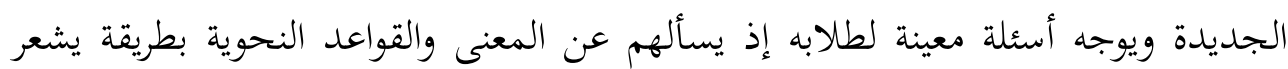
معها الطالب بأنه يؤدي عملا مبتورا (الدليمي الوائلي، 2003: 60).

أما هذه الطريقة فإن أنصارها الطريقة الفضلى في تحقيق الأهداف المرسومة لتعليم النحو لأن يتم عن طريقها مزج القواعد بالتركيب وبالتعبير الصحيح المؤدي إلى رسوخ اللغة وأساليبها رسوخا مقرونا بخصائصها الإعرابية. وهذه الطريقة هي المثلى في تعليم النحو لأنها تعتمد أول ما لـا تعتمد على المران المستمد من هذا الاستعمال الصحيح للغة من كافة مجالتها الحيوية وسائر أحوالها في مجرى الاستعمال الواقعي.

وأما خصوم هذه الطريقة فإنها تعمل على إضعاف الطلبة باللغة العربية وجهلهم لأبسط قواعدها لأن مبدأ التقديم بنص يناقشه المعلم مع طلابه ثم يستخرج منه الأمثلة التي تعينه على استباط القاعدة التي يراد تعليمها، إنما هو ضياع الوقت لأن الموضوع لاعلاقة له بالقواعد النحوية التي هي موضوع الدرس الحقيقي. وهذه الطريقة تشغل الطالب بموضوع الإنشاء فتصرفه عن قاعدة النحو المراد شرحها (شخاطة، 213).

هـ. خلاصة

الخلاصات في هذه الورقة هي: 1) القواعد النحوية تتكون من القواعد النظرية والقواعد الوظيفية. الأولى لثروة عالم المعارف النحوية والثانية تم تحديدها محتاجة إلى تعزيز ممارسة المهارات اللغوية لا سيما في تنمية قدرة الكتابة شفهية وتحريرية. 2) محاولة تيسير القواعد النحوية قد نشأت منذ الزمن القديم حتى الزمن الحديث من خلال تصنيف الكتابة بروح التجديد النحوي حيث يهتم بتحديد القواعد الوظيفية أو التطبيقية ويهمل القواعد النظرية أو القواعد المعرفية. 3) اتقان القواعد النحوية يفتقر إلى طريقة التعليم المناسبة باحتياجة الطالبين حيث يمكن أن تدمج المواد النحوية في تعليم المهارة اللغوية خاصة في القراءة والكتابة، بأن الطالبين أكثر فهما ببدء شرح النصوص لمجاوزة القاعدة النحوية. 
Mohammed, Elsamani Mohammed Musa and M T. Habeebullah, "Teaching of Arabic Grammar: Problems and Solutions", 5th International Symposium, IntSym 2015, SEUSL.

ابن عقيل، بهاء الدين عبد الله. شرح ابن عقيل (إندونيسيا: دار إحياء الكتب العربية، دون سنة) أبو بكر، عبد اللطيف عبد القادر. تعليم اللغة العربية الأطر والإجراءات (عمان: مكتبة الضامري، .$(1990$

الأهدل، محمد بن أحمد بن عبد الباري. الكواكب الدربية شرح متممة الآجرومية (إندونيسيا: دار إحياء الكتب العربية، دون السنة)

جاهمي، محمد. "واقع تعليم النحو العربي في المرحلة الثانوية"، مجلة العلوم الإنسانية، العدد 9، .2005

$$
\text { الخطيب، محمد إبراهيم. طرائق تعليم اللغة الغربية (الأردن: مكتبة التوبة، 2003) }
$$
الدليمي، طه علي حسين. الوائلي، سعاد عبد الكريم. الطرائق العملية في تلريس اللغة العببية (الأردن: دار الشروق، 2003).

السيد، محمود أحمد. في طرائق تلدريس اللغة العببية (دمشق: منشورات جامعة دمشق، 1997). الشجراوي، عزام عمر. النحو التطبيق (القاهرة: دار المعارف، 1991). شحاتة، جودت الركابيحسن. تعليم اللغة العببية بين النظرية والتطبيق (القاهرة: الدار المصدرية

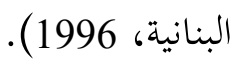

شحاتة، حسن. تعليم اللغة العربية بين النظرية والتطبيق (القاهرة: الدار المصدرية البنانية، 1996). الصميلي، يوسف. اللغة العربية زطرق تعليمها نظرية وتطبيقيا (بيروت: المكتبة العصرية، 1998) الصنهجي، أبو عبد الله محمد بن محمد بن داود، (دون سنة). متن الأجرومية. ضيف، شوقي. تجديد النحو (القاهرة: دار المعارف، 1986). طواهرية، مسعود، تيسير النحو التعليم: دراسة في المنهج وآليات إصلاة البيداغوجية، جامعة الوادي

عبد الله عبد، الحميد و ناصر عبد الله الغالي، أسس إعلداد الكتب التعليمية لغير الناطقين بالعربية، (الرياض: دار الغالي).

عطا، إبراهيم محمد. المرجع في تلديس اللغة العربية (القاهرة: مصر الجديدة، 2005). 
مدكور، علي أحمد. تعليم فنون اللغة العربية (القاهرة: دار الشواف، 1991). معروف، نايف محمود. خصائص العربية وطرائق تلدريسها، (لبنان: دار النغائس، 1991). ناصف، حفني بك وآخرون. قواعد اللغة العربية (سورابايا: بوغكول إنداه، 1997). الناقة، محمود الكامل ورشدي أحمد طعيمة. طرائق تعليم اللغة العربية لغير الناطقين بها (إيسيسكو: منشورات المنظمة الإسلامية للتربية والعلوم والثقافة، 2003)

نصار دين، " تعليم النحو باستخدام كتاب تجديد النحو لشوقي ضيف"، Cordova Journal،

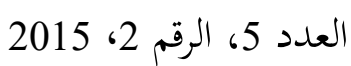

الهاشمي، عابد توفيق. الموجه العملي لمدرس اللغة العببية (بيروت: مؤسسة الرسالة، 1983). 